\title{
Obstrução intestinal em bovinos associada ao consumo de Stylosanthes sp. (Fabaceae Papilionoideae) ${ }^{1}$
}

\author{
Daniel G. Ubiali², Rafael G.F. Silva ${ }^{3}$, Leonardo P. Oliveira ${ }^{4}$, Luiz G. de Moraes ${ }^{4}$, Flávio \\ H.B. Caldeira ${ }^{2}$, Caroline A. Pescador ${ }^{5}$, Marcos de A. Souza ${ }^{5}$ e Edson M. Colodel ${ }^{5 *}$
}

\begin{abstract}
Ubiali D.G., Silva R.G.F., Oliveira L.P., Moraes L.G., Caldeira F.H.B., Pescador C.A. \& Colodel E.M. 2013. [Intestinal obstruction in cattle consuming Stylosanthes sp. (Fabaceae Papilionoideae).] Obstrução intestinal em bovinos causada pelo consumo de Stylosanthes sp. (Fabaceae Papilionoideae). Pesquisa Veterinária Brasileira 33(2):148-154. Departamento de Clínica Médica Veterinária, Faculdade de Agronomia e Medicina Veterinária e Zootecnia, Universidade Federal de Mato Grosso, Av. Fernando Corrêa da Costa 2367, Bairro Boa Esperança, Cuiabá, MT 78068-900, Brazil. E-mail: moleta@ufmt.br

The clinical and pathological findings of intestinal obstruction caused by phytobezoars in cattle consuming Stylosanthes sp. on three farms in Mato Grosso, Brazil, are described. The morbidity varied from 3.3 to $15 \%$ and the mortality was $100 \%$. The animals stayed on pastures with predominance of Stylosanthes $\mathrm{sp}$. for at least 60 days. The overall clinical picture was apathy followed by episodes of diarrhea or reduced feces and separation from the herd. Individual clinical signs were abdominal colic characterized by anorexia, discomfort, gastrointestinal hypomotility, dehydration, increased abdominal size, sweating, vocalization, sternal or lateral recumbence with the head on the flank. The clinical course lasted from 2 to 7 days. At necropsy, duodenal or pyloric obstruction was caused by ovoid phytobezoars of $2-4 \mathrm{~cm}$ diameter; in the area of obstruction friable intestinal tissue with intense swelling, congestion, edema, and reddish mucosa was found. The rumen, abomasum and duodenum proximal to the site of obstruction was filled with greenish liquid, and absence of food contents was observed distally to the phytobezoars. Histologically, at the site of obstruction, the duodenum exhibited diffuse necrosis of the mucosal surface, thickening of the wall by submucosal edema, neutrophilic infiltration, fibrin deposition, necrosis of smooth muscle fibers, and marked congestion or hemorrhage. Pasture with the predominance of Stylosanthes sp. is a serious problem due to the possibility of phytobezoar formation, thus leading to intestinal obstruction and high mortality rates in cattle.
\end{abstract}

INDEX TERMS: Plants causing mechanical injury, Stylosanthes sp., Fabaceae Papilionoideae, cattle diseases, intestinal obstruction, beef cattle.

RESUMO.- 0 objetivo deste trabalho é descrever, em três propriedades rurais no Estado de Mato Grosso, a epidemiologia, o quadro clínico e o patológico da obstrução intesti-

\footnotetext{
${ }^{1}$ Recebido em 23 de junho de 2012.

Aceito para publicação em 3 de julho de 2012.

${ }^{2}$ Programa de Pós-Graduação em Ciências Veterinárias, Faculdade de Agronomia, Medicina Veterinária e Zootecnia (Famev), Universidade Federal de Mato Grosso (UFMT), Av. Fernando Corrêa da Costa 2367, Boa Esperança, Cuiabá, MT 78068-900, Brasil.

${ }^{3}$ Programa de Pós-Graduação em Ciência Animal, Famev-UFMT, Boa Esperança, Cuiabá, MT.

${ }^{4}$ Graduação em Medicina Veterinária, Famev-UFMT, Cuiabá, MT.

${ }^{5}$ Departamento de Clínica Médica Veterinária, Famev-UFMT, Cuiabá, MT. *Autor para correspondência: moleta@ufmt.br
}

nal por fitobezoares em bovinos que pastoreavam em piquetes com predomínio de Stylosanthes sp. pelo menos 60 dias. A morbidade variou de $3,3 \%$ a $15 \%$ e a mortalidade foi de $100 \%$. 0 quadro clínico foi de cólica abdominal caracterizado por apatia, anorexia, inquietação, desconforto, sudorese e vocalização, seguido por episódios de diarreia ou diminuição da produção fecal, desidratação, hipomotilidade gastrintestinal, aumento do volume abdominal, decúbito esternal ou lateral com a cabeça voltada para o flanco e morte. 0 curso clínico foi de 2-7 dias. A principal alteração notada durante a necropsia dos bovinos foi a obstrução intestinal por fitobezoar ovoide de $2-5 \mathrm{~cm}$ de diâmetro, frequentemente no duodeno, próximo ao piloro, ocasionalmente em sua porção média. Na área de obstru- 
ção notou-se a necrose da parede intestinal que estava enegrecida e intensamente demarcada em relação a segmento adjacente normal, além de intenso espessamento associado a edema, congestão e hemorragia. 0 abomaso e os segmentos intestinais anteriores a obstrução apresentavam-se repletos de conteúdo alimentar líquido e posteriormente estava com ausência de conteúdo. 0 rúmen frequentemente tinha grande quantidade de conteúdo liquido a pastoso. Em todos os bovinos necropsiados múltiplas estruturas sólidas, arredondadas ou ovoides, esverdeadas (fitobezoares) foram observadas no abomaso. Estes achados indicam que pastagens com predomínio de Stylosanthes sp. predispõem a formação de fitobezoares, os quais podem levar à obstrução intestinal e morte em bovinos.

TERMOS DE INDEXAÇÃO: Plantas que causam lesões mecânicas, Stylosanthes sp., Fabaceae Papilionoideae, doenças de bovinos, obstrução intestinal, bovinos de corte.

\section{INTRODUÇÃO}

Em bovinos, relata-se obstrução intraluminal de intestino delgado associado com bezoares (Afonso et al. 2008), enterólitos (Navarre \& Roussel 1996), areia (Cebra et al. 1996), outros corpos estranhos (Martins et al. 2004), intussuscepção (Pravettoni et al. 2009) e volvo (Pearson \& Pinsent 1977, Garry et al. 1988). Bezoares são estruturas sólidas, cúbicas ou ovoides formadas no interior do sistema gastrointestinal, a partir de resíduos vegetais ricos em fibras indigeríveis (fitobezoares), em pelos (tricobezoares) ou em combinação entre materiais originários de plantas e de pelos (tricofitobezoares) (Bath \& Bergh 1979).

Plantas como Agave sisalana (Riet-Correa et al. 2011), Melia azedarach (Knight \& Walter 2001), Opuntia ficus-indica (Afonso et al. 2008), Pennisetum purpureum (Hasunuma et al. 2011), Phleum pratense (Sherman 1981), Stipagrostis foliata e S. obtusa (Bath \& Bergh 1979) são relacionadas à formação de fitobezoares em ruminantes.

0 gênero Stylosanthes é originário das Américas Central e do Sul, e representa um grupo importante de leguminosas utilizadas como pastagens em ambientes tropicais e subtropicais. No Brasil ocorrem 25 espécies, encontradas principalmente no Cerrado, sendo a maioria perene, com sistema radicular bem desenvolvido, tolerantes a seca, com grande capacidade de adaptação a solos de baixa fertilidade e fixação de nitrogênio no solo. As principais espécies cultivadas como plantas forrageiras para alimentação de bovinos, bufalinos, caprinos e ovinos são: S. capitata, S. macrocephala e S. guianensis (Embrapa 2007, Chandra 2009, Du et al. 2009, Thang et al. 2010).

O objetivo deste trabalho é descrever o quadro clínico- -patológico e aspectos epidemiológicos de três surtos de obstrução intestinal por fitobezoares em bovinos, associados ao consumo de Stylosanthes sp. no Estado de Mato Grosso.

\section{MATERIAL E MÉTODOS}

Três casos de mortalidade em bovinos foram acompanhados no Estado de Mato Grosso. A equipe do LPV/UFMT (Laboratório de Patologia Veterinária/Universidade Federal de Mato Grosso) realizou visitas nos seguintes municípios: Alto Araguaia (Propriedade 1) em janeiro de 2010, Chapada dos Guimarães (Propriedade 2) em outubro de 2011 e Santo Antônio do Leste (Propriedade 3) em abril de 2012. Durante as visitas os piquetes de pastoreio e os rebanhos foram inspecionados. Coletaram-se informações sobre histórico clínico e aspectos epidemiológicos através de entrevistas com proprietários, vaqueiros e veterinários responsáveis nas respectivas propriedades (Quadro 1).

Realizaram-se necropsias em seis bovinos na Propriedade 1, em um na Propriedade 2 e em três na Propriedade 3. Coletaram-se encéfalo, fragmentos de intestino, abomaso, rúmen, retículo, omaso, baço, fígado, coração, pulmão e rim em solução formalina $10 \%$, os quais foram processados rotineiramente para estudo histológico (Allen 1992).

Amostras botânicas foram coletadas nas áreas pastejadas e encaminhadas para identificação no Herbário Central da UFMT. Realizou-se análise bromatológica de Stylosanthes sp. e dos fitobezoares encontrados durante as necropsias, segundo metodologia de Silva \& Queiroz (2002) (Quadro 2). Adicionalmente coletaram-se amostras de solo da Propriedade 3 para análise química e física (Camargo et al. 2009) no Laboratório Solo Análise ${ }^{\circledR}$, em Primavera do Leste, MT.

\section{RESULTADOS}

As amostras botânicas foram classificadas como Stylosanthes capitata. Em comum nas três propriedades constatou-

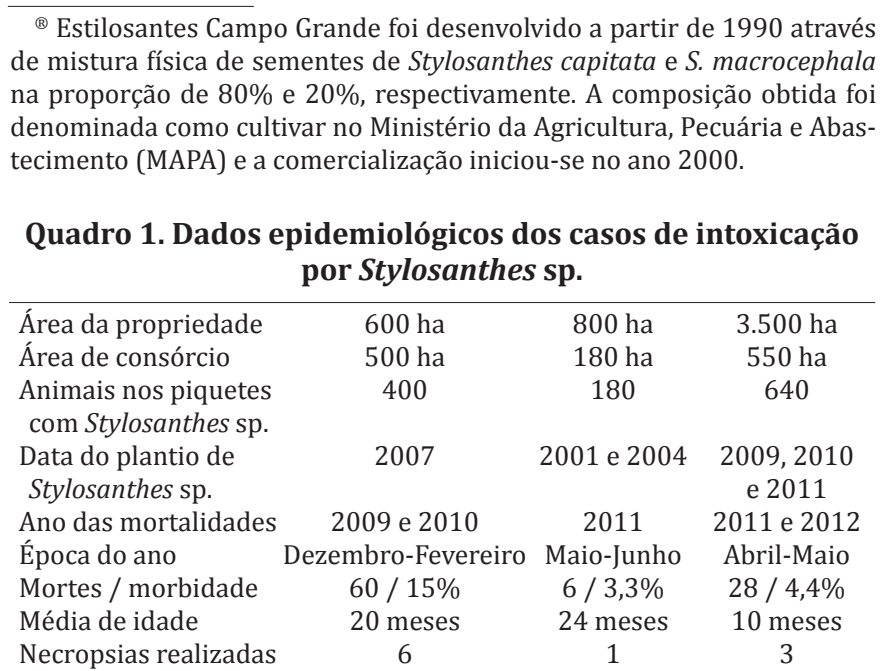

Quadro 2. Médias de análise bromatológica de Stylosanthes capitata coletados em piquetes e de fitobezoares obtidos em necropsias

\begin{tabular}{|c|c|c|c|c|c|c|c|c|c|c|}
\hline & $\begin{array}{c}\text { Matéria } \\
\text { seca }\end{array}$ & $\begin{array}{c}\text { Matéria } \\
\text { orgânica* }\end{array}$ & $\begin{array}{l}\text { Matéria } \\
\text { mineral* }\end{array}$ & $\begin{array}{l}\text { Proteína } \\
\text { bruta* }\end{array}$ & FDN* & FDA $^{*}$ & FDNi* & $\begin{array}{l}\text { Hemice- } \\
\text { lulose* }\end{array}$ & Celulose* & Lignina* \\
\hline & & & & & & & & & & \\
\hline Stylc & $31,84 \%$ & $84,26 \%$ & $15,74 \%$ & $10,33 \%$ & $52,80 \%$ & 33,9 & $28,22 \%$ & $18,88 \%$ & $6,07 \%$ & $12,11 \%$ \\
\hline Brachiaria brizantha** & $53,72 \%$ & $90,07 \%$ & $9,92 \%$ & $4,01 \%$ & $69,84 \%$ & $39,83 \%$ & $23,44 \%$ & $30,01 \%$ & $23,44 \%$ & $6,47 \%$ \\
\hline
\end{tabular}

*\% com base na matéria seca. FDN = fibra em detergente neutro; FDA = fibra em detergente ácido; FDNi = fibra em detergente neutro insolúvel. **Adaptado de Paula et al. (2010). 
-se que predominavam solos arenosos (Fig.1), os pastos eram formados pelo cultivar comercial Estilosantes Campo Grande $^{\circledR}$ (Embrapa 2007), consorciado com espécies de Brachiaria, e o sistema de criação era extensivo. No momento do plantio os criadores adotaram proporções recomendadas comercialmente para implantação da pastagem: $80 \%$ de braquiária e $20 \%$ de Estilosantes Campo Grande ${ }^{\circledR}$ (Embrapa 2010).

Nas três propriedades, durante a inspeção dos piquetes, notaram-se fitobezoares misturados ao conteúdo gastrintestinal putrefeito ou, no campo, carcaças de bovinos que tinham morridos com histórico clínico similar aos que estavam doentes. Os protocolos de vacinação estavam em dia, para raiva, botulismo, carbúnculo sintomático e febre aftosa.

Análises bromatológicas dos fitobezoares evidenciaram grande quantidade de fibras, mensurados pela fibra em detergente neutro (FDN), fibra em detergente ácido (FDA), fibra detergente neutro insolúvel (FDNi) e lignina em comparação com os resultados obtidos do Stylosanthes capitata (Quadro 2).

A análise de solo da Propriedade 3 demonstrou classe textural arenosa, com $890 \mathrm{~g} / \mathrm{dm}^{3}$ de areia, 90 e $20 \mathrm{~g} / \mathrm{dm}^{3}$ de argila e silte respectivamente. Os níveis de fósforo (P) foram de $0,96 \mathrm{mg} / \mathrm{dm}^{3}$, alumínio (Al) $0,36 \mathrm{cmolc} / \mathrm{dm}^{3}$ e acidez potencial $(\mathrm{H}+\mathrm{Al}) 2,25 \mathrm{mg} / \mathrm{dm}^{3}$.
Propriedade 1. Possui área de 600 hectares (ha) e o rebanho era composto por 400 bovinos em sistema de cria e recria. A pastagem foi formada com sementes de B. brizanta e Estilosantes Campo Grande ${ }^{\circledR}$ na estação das águas em 2007 na proporção de 80:20, respectivamente. Em dezembro de 2009 morreram 15 bovinos, em janeiro de 2010 morreram outros 35 bovinos. Durante a inspeção dos pastos, verificou-se que havia predomínio acentuado da leguminosa (Fig.1). 0 quadro clínico era variável, inicialmente com isolamento do lote, prostração, apatia e inapetência, seguido de diarreia com conteúdo esverdeado em pouca quantidade. Notou-se cólica abdominal aguda, caracterizada por anorexia, seguido por sinais de desidratação, hipomotilidade gastrointestinal, desconforto, sudorese, vocalização, decúbito esternal ou decúbito lateral com a cabeça voltada para o flanco. 0 curso clínico variou de 3 a 7 dias. Os vaqueiros relataram que a maioria das carcaças foi encontrada nas proximidades ou dentro das fontes de água (Fig.2). Realizou-se necropsia em seis bovinos, quatro destes encontrados mortos, um encontrado em decúbito esternal com a cabeça voltada para o flanco e outro que estava no início do quadro clínico, isolado do rebanho, com inapetência e emagrecimento. Macroscopicamente, ao exame da carcaça, notava-se abdômen acentuadamente distendido e líquido ruminal fluindo pela cavidade nasal. Em cinco bovi-
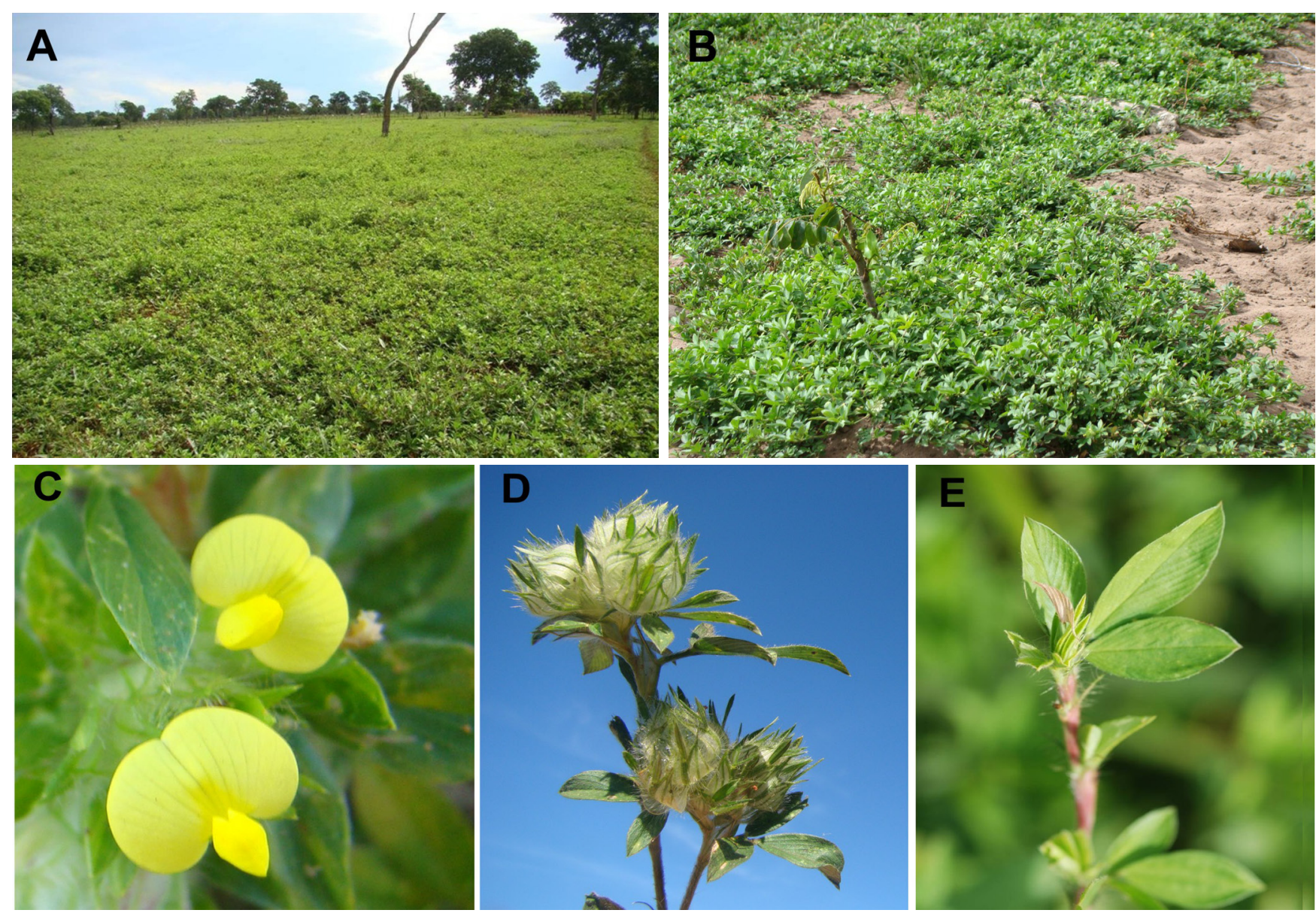

Fig.1. (A) Campo com predomínio de Stylosanthes sp. onde ocorreu mortalidade de bovinos causada por obstrução intestinal por fitobezoares, Alto Araguaia/MT, em janeiro de 2010. (B) Stylosanthes sp. em solo arenoso. Santo Antônio do Leste/MT, em abril de 2012. (C-E) Inflorescência, frutificação e folhas de Stylosanthes capitata. Santo Antônio do Leste/MT, em abril de 2012. 

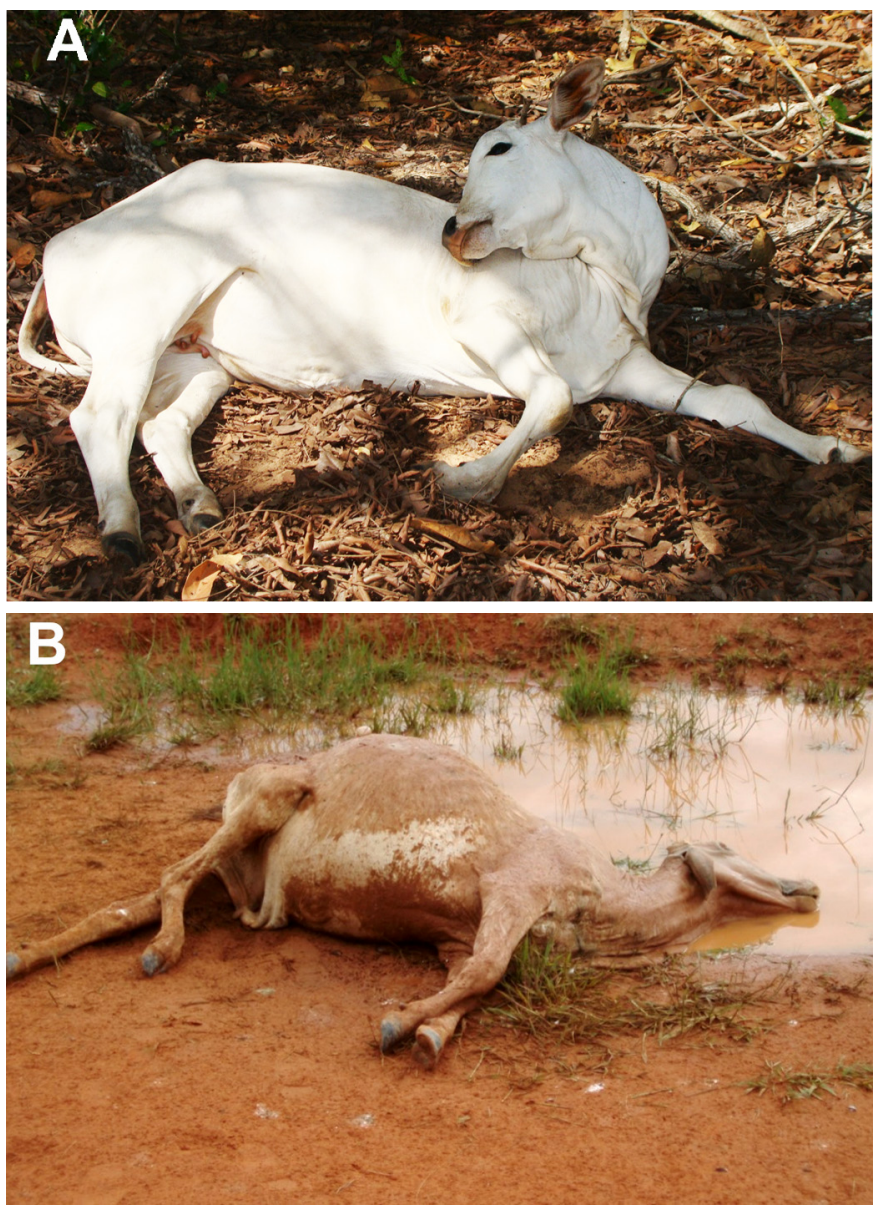

Fig.2. Bovinos com obstrução intestinal. (A) Bezerro com oito meses de idade em decúbito lateral com a cabeça voltada para o flanco. Santo Antônio do Leste/MT. (B) Carcaça encontrada próximo a uma poça de água. Nota-se acentuada distensão abdominal. Alto Araguaia/MT.

nos necropsiados, a principal alteração foi obstrução intestinal na região pilórica (um bovino), no duodeno proximal (dois bovinos) e no duodeno médio (dois bovinos) por estrutura verde-oliva, firme, ovoide (fitobezoar), envolto por membrana brancacenta mucoide. No local da obstrução notaram-se aumento da espessura da parede, hiperemia e edema mural; a mucosa estava friável com uma linha demarcatória hiperêmico-hemorrágica separando a mucosa normal da friável (Fig.3). 0 rúmen, abomaso e duodeno, nas porções proximais ao local da obstrução, estavam repletos de conteúdo líquido esverdeado, e no intestino, nas porções distais ao local de obstrução, havia ausência de conteúdo. Não se notou obstrução em um dos bovinos sacrificado no início do quadro clínico, mas similar aos demais havia diferentes fitobezoares livres no abomaso, com forma ovoide a poliédrico ou esférico com tamanho de 0,5$18 \mathrm{~cm}$, na maioria com tamanho de $4-8 \mathrm{~cm}$, com peso seco de 9-458g; a consistência era firme, a coloração variava de verde-oliva a marrom-escuro e a sua estrutura era composta por inúmeras fibras vegetais finas (Fig.3). Na ampola retal havia quantidade moderada de conteúdo mucoso ocasionalmente envolvendo escassa quantidade de fezes.

Na avaliação histológica do local da obstrução havia na mucosa necrose difusa, edema, infiltrado neutrofílico, intensa deposição de fibrina, e na submucosa, necrose aleatória de fibras musculares lisas e marcada congestão e hemorragia. Na superfície apical do epitélio intestinal havia grande quantidade de bactérias bacilares basofílicas. Os demais órgãos não apresentaram alterações significativas.

Ao todo morreram 60 bovinos, (15\%) do rebanho. No início de fevereiro de 2010 retiraram-se os animais das áreas invadidas por Stylosanthes sp., que foram transferidos para um pasto com Brachiaria brizantha. Após a troca dos piquetes relatou-se ainda a morte de outros 10 bovinos.

Propriedade 2. Possui 800 ha, com aproximadamente 800 bovinos de diversas idades, de cria, recria e engorda. Nos anos de 2001 e 2004, dois piquetes um de 60 e outro de 120 ha, respectivamente, foram formados pelo consórcio de B. brizantha e Estilosantes Campo Grande ${ }^{\circledR}$ na proporção de 80:20.

No ano de 2006 o proprietário observou uma inversão no consórcio entre as forragens. Estrategicamente foram utilizadas duas formas de controle; inicialmente alojou-se um rebanho a fim de promover uma alta pressão de pastejo (3 bovinos adultos/ha), no entanto, notou-se um efeito contrário ao desejado, com aumento do predomínio da leguminosa. A segunda forma estratégica foi a aplicação de 2,4-D (ácido diclorofenoxiacético) em um hectare do piquete onde havia predomínio de Stylosanthes sp. Segundo a avaliação visual do proprietário, a aplicação havia causado o desaparecimento da leguminosa, porém 5 meses após, quando iniciou-se a estação chuvosa, a leguminosa restabeleceu-se vigorosamente e manteve-se no piquete em maior proporção do que $B$. brizantha.

Em junho de 2011, nos dois piquetes consorciados estavam alojados 180 bovinos adultos. Relatou-se mortalidade de quatro bovinos com quadro clínico de cólica abdominal aguda; em agosto houve morte de outros dois bovinos com sinais clínicos semelhantes. A idade dos bovinos variou de 9 meses a 4 anos. Segundo o relato do proprietário os animais apresentavam inicialmente prostração e isolamento do rebanho, seguido de decúbito esternal, aumento do volume abdominal, retração do globo ocular no interior da órbita, seguido de decúbito lateral e morte com quadro clínico de 2-5 dias. Durante a visita em outubro de 2011, verificou-se na inspeção dos piquetes visualmente que Stylosanthes sp. predominava em proporções acima de $90 \%$. 0 médico veterinário responsável realizou necropsia em um bovino e relatou a presença de fitobezoares no abomaso, no entanto o intestino não foi examinado.

Propriedade 3. A área total de pastagens é de 3.500 ha e o sistema de criação dos bovinos é exclusivamente de cria. Realizou-se o plantio de sementes de Estilosantes Campo Grande ${ }^{\circledR}$ nos anos de 2009, 2010 e 2011, num total de 550 ha; utilizaram-se as gramíneas $B$. brizantha e $B$. decumbens. Sobre essa área pastejaram lotes que somaram 640 bovinos, entre vacas e bezerros.

Durante a visita em abril de 2012 notou-se o predomínio acentuado de Stylosanthes sp. nos piquetes inspecionados. Relatos dos responsáveis informaram que o predomínio de Stylosanthes sp. nas áreas de consórcio com $B$. decumbens ocorreu em grande parte devido ao ataque de cigarrinha 

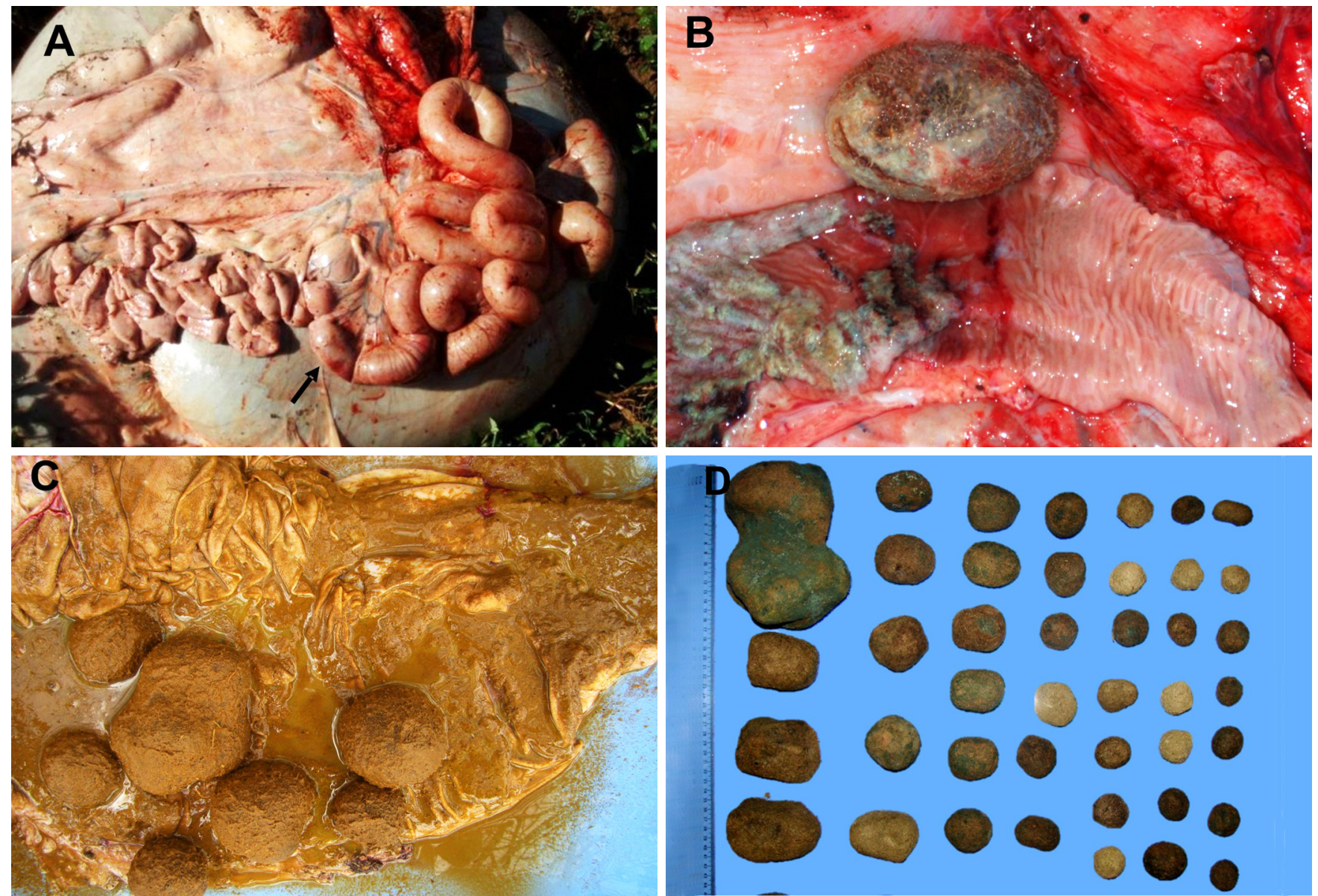

Fig.3. Obstrução intestinal em bovinos. (A) Exame macroscópico do duodeno apresentando-se repleto na porção proximal à obstrução por fitobezoar (seta) e com ausência de conteúdo na porção distal à obstrução. (B) Mucosa duodenal com intenso edema, congestão e uma linha vermelha associada à presença de fitobezoar envolto por conteúdo fibrinoso. (C) Abomaso apresentando diversos fitobezoares. (D) Fitobezoares encontrados em necropsias.

(Homoptera: Cercopidae) à gramínea; nas áreas de consórcio com B. brizantha, o predomínio de Stylosanthes se deu por conta da pressão de pastejo e seletividade dos bovinos à gramínea.

Relatou-se mortandade de sete bovinos com sinais clínicos de cólica e desidratação no ano de 2011, mas não foram realizadas necropsias. Em abril e maio de 2012 ocorreram outros 21 casos clínicos semelhantes, sendo a maioria deles em bovinos com média de 8 meses de idade. 0 curso clínico variou de 3 a 6 dias. Durante visita dois bezerros apresentavam aumento de volume e dor abdominal, decúbito lateral com a cabeça voltada para o flanco (Fig.2) e desidratação acentuada. Estes dois bovinos foram submetidos à eutanasia e necropsiados. Em ambos havia obstrução na porção inicial do duodeno, aproximadamente $60 \mathrm{~cm}$ distalmente ao piloro, por fitobezoar esférico com $1,5 \mathrm{~cm}$ de diâmetro; o duodeno proximal à obstrução, o rúmen e o abomaso apresentaram grande quantidade de conteúdo verde e líquido, no abomaso havia diferentes quantidades de fitobezoares livres e de grande diâmetro. Na avaliação histológica do local da obstrução, havia na mucosa, necrose difusa, edema, infiltrado neutrofílico, intensa deposição de fibrina, grumos bacterianos basofílicos e marcada congestão e hemorragia na submucosa. Uma vaca com 14 anos de idade, sacrificada devido a quadro de emagrecimento tinha o abomaso distendido por conteúdo líquido e esverdeado e com sete fitobezoares de grande diâmetro (Fig.3), além de se notar mucosa abomasal finamente irregular e levemente espessada. Neste bovino notou-se vesícula biliar hiperêmica, com a parede espessada e lúmen intensamente distendido com conteúdo brancacento, glumoso e coagulado. Deste conteúdo houve crescimento puro de Escherichia coli.

\section{DISCUSSÃO}

Neste trabalho relacionamos o quadro clínico de cólica abdominal aguda em bovinos com a obstrução intestinal por fitobezoar devido ao consumo excessivo de Stylosanthes sp. Obtivemos históricos de mortalidade em bovinos que pastejam em áreas mal manejadas de consórcio estilosantes/ braquiária, sempre quando há predomínio da leguminosa, portanto esta planta deve ser considerada potencialmente tóxica, de ação direta, com importância maior para bovinos, sobretudo na região Centro-Oeste do Brasil.

Várias plantas podem causar lesões mecânicas no trato gastrointestinal em animais de interesse pecuário, incluindo a obstrução intestinal, obstrução esofágica e sobrecarga ruminal (Riet-Correa et al. 2011). Obstrução intestinal foi relatada em bovinos e a causa foi atribuída ao consumo 
de Pennisetum purpureum (capim napier) no Japão (Hasunuma et al. 2011). Casos de compactação ruminal ou obstrução por fitobezoares ocorrem em bovinos na região Nordeste do Brasil, quando alimentados com o bagaço do Agave sisalana (sisal), planta com grande quantidade de fibra de baixa digestibilidade que é utilizado para alimentação animal em épocas de seca (Riet-Correa et al. 2011). Melia azedarach (cinamomo) é descrita na África do Sul como causa de compactação ruminal e obstrução intestinal em bovinos (Knight \& Walter 2001), porém não há relatos similares no Brasil, apesar da abundância da planta na região Sul (Riet-Correa et al. 2011). Stipagrostis obtusa e $S$. foliata são arbustos da África do Sul dos quais as sementes são consumidas por ovinos e caprinos e que possuem tendência de unirem-se e formar fitobezoares no abomaso (Bath \& Bergh 1979). Sherman (1981) relatou um caso de obstrução intestinal por fitobezoar em um caprino nos Estados Unidos que consumia feno de Phleum pratense (timothy) ad libtum.

Notas Técnicas do Centro Nacional de Pesquisa em Gado de Corte (CNPGC/Embrapa) incentivam a consorciação do Estilosantes cultivar Campo Grande ${ }^{\circledR}$, principalmente no Cerrado, devido ao seu valor nutricional como pastagem para bovinos e também para melhoria da qualidade do solo. A consorciação máxima não deve ultrapassar 40\% de Stylosanthes spp. em relação a outras gramíneas (Embrapa 2007, 2010). Nas três propriedades relatadas ocorreram falhas no consórcio entre a leguminosa e a gramínea, fato verificado durante a inspeção dos piquetes na qual se notou que a proporção atingiu de 80 a $90 \%$ da área, sendo essa condição associada à formação de fitobezoares. Evidência adicional está relacionada à diminuição progressiva da mortalidade após a retirada do rebanho da área problema.

Dentre as características do Stylosanthes sp. destacamse sua capacidade de fixação biológica de nitrogênio (Embrapa 2007, Chandra 2009, Thang et al. 2010), boa adaptação em áreas de Cerrado (Embrapa 2007), ressemeadura natural (Rodrigues et al. 2010), tolerância a solos ácidos, ricos em alumínio e deficientes em fósforo (Du et al. 2009), excelente desenvolvimento vegetativo, tolerância a pragas e doenças (Veasey et al. 1999) e sistema radicular bem desenvolvido (Chandra 2009). Essas características tornam a utilização desta leguminosa comercialmente atrativa aos pecuaristas. No entanto, há questões divergentes, como por exemplo, seu alto potencial de competição com as gramíneas e de sua grande persistência no ambiente. Os solos predominantemente arenosos analisado na Propriedade 3 e constatados nas outras duas, além da alta pressão de pastejo e ataque de pragas, contribuíram na dispersão da leguminosa e no desaparecimento da braquiária. Devido à dificuldade em controlar a expansão da população de Stylosanthes sp. tornam-se necessários estudos complementares para desenvolvimento de métodos de manejo para evitar a desproporção entre gramínea/leguminosa. As mortalidades ocorreram após um período médio de três anos do início do consórcio.

Embora seja incomum a formação de fitobezoares (Martins et al. 2004), a condição de manejo alimentar baseada em fornecimento de alimentos ricos em fibras é um fator de risco importante para essa formação (Hasunuma et al. 2011). Afonso et al. (2008) descreveram 16 casos de obstrução gastrointestinal por fitobezoares em bovinos originários de propriedades que tinham em comum a dieta composta predominantemente por Opuntia ficus-indica (palma-forrageira). Van Soest (1964) afirma que as leguminosas são plantas ricas em lignina. Em ensaios bromatológicos encontramos 33,87\% desta fibra nos fitobezoares e $12,11 \%$ no Stylosanthes capitata. Nos fitobezoares detectou-se alto valor de FDNi (73,07\%), em contraste com os baixos níveis de elementos digestíveis como proteína bruta, hemicelulose e celulose. Essa relação causa uma maior permanência da ingesta no abomaso, facilitando a agregação das fibras, portanto pressupomos que a lignina tem importância na gênese dos fitobezoares. Estudos mais detalhados são necessários para elucidar o mecanismo de agregação das partículas vegetais e formação dessas estruturas.

0 quadro de emagrecimento e fezes pastoso-esverdeadas, não associado à obstrução, carece de melhor entendimento, uma vez que notamos abomaso repleto de conteúdo líquido com fitobezoares livres em todas as necropsias, no entanto são escassas as evidencias para afirmar se esses fitobezoares estão envolvidos na diminuição da eficiência digestiva devido a pressão mecânica ou atrito constante; observou-se macroscopicamente a mucosa do abomaso espessa e rugosa. Um caso de colecistite bacteriana por Escherichia coli, ocorreu possivelmente devido à infecção bacteriana ascendente pelo colédoco sem obstrução intestinal.

Estudos experimentais para elucidação da patogênese da obstrução intestinal são raros. Reutgers et al. (1988) estudaram em bovinos a atividade elétrica do duodeno após oclusão extraluminal e relataram desorganização abrupta dos complexos mioelétricos migratórios, produzindo padrões de peristaltismo irregulares; em conseqüência, os animais desenvolvem cólica abdominal aguda. Possivelmente isso tenha ocorrido nos animais no nosso trabalho, especificamente os que apresentaram obstrução intraluminal.

A observação de morte de bovinos próximos a fontes de água e o conteúdo ruminal com excessiva quantidade de líquido pode ser explicado pela desidratação associada à obstrução, e consequente busca por água para dessedentação. Neste estudo relacionamos o quadro clínico à cólica abdominal aguda e a causa da morte ao choque circulatório devido à obstrução intestinal (Stokhof 2004). Provavelmente, o choque seja de origem séptica devido à necrose da mucosa e parede intestinal, facilitando a absorção de toxinas e invasão de microorganismos. Além disso, outros fatores decorrentes da obstrução intestinal também podem ter contribuído no quadro clínico-patológico, como dor, desidratação, alcalose metabólica e aumento de cloretos séricos e uréia (Mosier 2009). Tokarnia et al. (2012) citam, que alguns animais morrem pela ruptura do intestino e consequente peritonite. Em nosso estudo não se observou essa sequencia de eventos.

Agradecimentos.- Aos médicos veterinários Francisco Pariz, Adriana Pariz, Lorenzo Pacheco e Rogaciano Arruda pelas informações e participação técnica no desenvolvimento deste estudo. Trabalho financiado pelo Instituto Nacional de Ciência e Tecnologia Para o Controle das Intoxicações por Plantas (CNPq, proc. 573534/2008-2). 


\section{REFERÊNCIAS}

Afonso J.A.B., Pereira A.L.L., Vieira A.C.S., Mendonça C.L., Costa N.A. \& Souza M.I. 2008. Alterações clínicas e laboratoriais na obstrução gastrintestinal por fitobezoários em bovinos. Revta Bras. Saúde Prod. Anim. 9(1):91-102.

Allen T.C. 1992. Hematoxylin and eosin, p.53-58. In: Prophet E.B., Mills B., Arrington J.B. \& Sobin L.H. (Eds), Laboratory Methods in Histotechnology. Armed Forces Institute of Pathology, Washington, DC. 279p.

Bath G.F. \& Bergh T. 1979. A specific form of abomasal phytobezoar in goats and sheep. J. South African Vet. Assoc. 50(2):69-72.

Camargo O.A., Moniz A.C., Jorge J.A. \& Valadares J.M.A.S. 2009. Métodos de Análise Química, Mineralógica e Física de Solos do Instituto Agronômico de Campinas (Edição revisada). Bolm Téc. 106, IAC, Campinas. 77p.

Cebra C.K., Cebra M.L. \& Garry F.B. 1996. Gravel obstruction in the abomasum or duodenum in two cows. J. Am. Vet. Med. Assoc. 209(7):12941296.

Chandra A. 2009. Diversity among Stylosanthes species: Habitat, edaphic and agro-climatic affinities leading to cultivar development. J. Environ. Biol. 30(4):471-478.

Embrapa 2007. Cultivo e uso do estilosantes-campo-grande. Comum. Téc. 105, Embrapa Gado de Corte, Campo Grande, MS. 11p.

Embrapa Gado de Corte 2010. Uso correto do estilosantes em pastagens consorciadas. Nota Técnica, Embrapa-CNPGC, Campo Grande, MS.

Du Y.M., Tian J., Liao H., Bai C.J., Yan X.L. \& Liu G.D. 2009. Aluminum tolerance and high phosphorus efficiency helps Stylosanthes better adapt to low-P acid soils. Ann. Bot. 103:1239-1247.

Garry F., Hull B.L., Rings D.M. \& Hoffsis G. 1988. Comparision of naturally occurring proximal duodenal obstruction and abomasal volvulus in dairy cattle. Vet. Surg. 17(4):226-230.

Hasunuma H., Matsumoto D., Kirino Y., Sasa T., Fushimi Y., Ikeda T., Tshering C. \& Takagi M. 2011. Acute colic possibly caused by phytobezoar derived from Napier grass in 5 Japanese Black cows reared in the same farm. J. Vet. Med. Sci. 73(8):1093-1096.

Knight A.P. \& Walter R.G. 2001. A Guide to Plant Poisoning of Animals in North America. Teton New Media, Jackson, WY. 367p.

Martins A.M.C.R.P.F., Leme M.C.M., Portugal M.A.S.C., Baldassi L. \& Margatho L.F.F. 2004. Presença de corpos estranhos no aparelho digestório dos bovinos. Arqs Inst. Biológico, São Paulo, 71(1):83-87.

Mosier D.A. 2009. Desordens vasculares e trombose, p.63-100. In: McGavin M.D. \& Zachary J.F. (Eds), Bases da Patologia em Veterinária. 4aa ed. Mosby Elsevier, Rio de Janeiro.
Navarre C.B. \& Roussel A.J. 1996. Gastrointestinal motility and disease in large animals. J. Vet. Intern. Med. 10(2):51-59.

Paula N.F., Zervoudakis J.T., Cabral L.S., Carvalho D.M.G., Hatamoto-Zervoudakis L.K., Moraes E.H.B.K. \& Oliveira A.A. 2010. Frequência de suplementação e fontes de proteína para recria de bovinos em pastejo no período seco: desempenho produtivo e econômico. Revta Bras. Zootec. 39(4):873-882.

Pearson H. \& Pinsent P.J.N. 1977. Intestinal obstruction in cattle. Vet. Rec. 101(9):162-166.

Pravettoni D., Morandi N., Rondena M., Riccaboni P., Zani D.D., Scandella M. \& Belloli A.G. 2009. Repeated occurrence of jejuno-jejunal intussusception in a calf. Can. Vet. J. 50:287-290.

Riet-Correa B., Riet-Correa G. \& Riet-Correa F. 2011. Plantas que causam alterações mecânicas ou traumáticas em ruminantes e equinos, com ênfase em Stipa spp. (Gramineae). Pesq. Vet. Bras. 31(6):516-520.

Rodrigues A.P.D.C., Laura V.A., Pereira S.R., Souza A.L. \& Freitas M.E. 2010. Temperatura de germinação em sementes de estilosantes. Revta Bras. Sementes 32(4):166-173.

Rutgers L.J.E., Kuiper R. \& Van der Velden M.A. 1988. Effects of experimental duodenal occlusion on electrical activity of the proximal duodenum in cattle. Res. Vet. Sci. 45:186-193.

Sherman D.M. 1981. Duodenal obstruction by a phytobezoar in a goat. J. Am. Vet. Med. Assoc. 178(2):139-140.

Silva D.J. \& Queiroz A.C. 2002. Análise de Alimentos: métodos químicos e biológicos. Editora UFV, Viçosa. 235p.

Stokhof A.A. 2004. The extracardiac peripheral circulation and shock, p.197-212. In: Dunlop R.H. \& Malbert C.H. (Eds), Veterinary Pathophysiology. Blackwell Publishing, Ames.

Thang C.M., Ledin I. \& Bertilsson J. 2010. Effect of feeding cassava and/ or Stylosanthes foliage on the performance of crossbred growing cattle. Trop. Anim. Health Prod. 42:1-11.

Tokarnia C.H., Brito M.F., Barbosa J.D., Peixoto P.V. \& Döbereiner J. 2012. Plantas Tóxicas do Brasil para Animais de Produção. 2ª ed. Editora Helianthus, Rio de Janeiro. 566p.

Van Soest P.J. 1964. Chemical procedures for evaluating forages symposium on nutrition and forage and pastures: new chemical procedures for evaluating forages. J. Anim. Sci. 23:838-845.

Veasey E.A., Werner J. C., Colozza M.T., Freitas J.C.T., Lucena M.A.C., Beisman D.A. \& Gerdes L. 1999. Avaliação de caracteres morfológicos, fenológicos e agronômicos em leguminosas forrageiras tropicais visando a produção de sementes. Bolm Indústr. Anim., Nova Odessa, 56(2):109-125. 